\title{
La maladie des nécroses annulaires superficielles des tubercules : une affection de la pomme de terre, due au virus $Y$
}

\author{
M Le Romancer, C Kerlan \\ INRA, station de pathologie végétale, 35650 Rennes, Le Rheu, France
}

(Reçu le 2 mai 1991; accepté le 23 septembre 1991)

\begin{abstract}
Résumé - Une affection particulière sur plants de pomme de terre de la variété Lola est apparue en 1988 au Liban et s'est maintenue en 1989 et 1990. Elle se caractérise par la présence, sur tubercules, d'importantes nécroses superficielles de formes variables, mais le plus souvent en arcs ou en anneaux. Ces lésions nécrotiques apparaissent au moment de la récolte et s'intensifient au cours des premières semaines de conservation.

La maladie est transmise à la descendance naturellement ou par inoculation mécanique à partir d'extraits de plantes infectées. Les techniques de détection mises en œuvre (test Elisa, microscopie électronique, indexage biologique, plantes pièges) révèlent l'existence de 2 virus, les virus $X$ et $Y$ de la pomme de terre, ce dernier étant systématiquement présent dans les plantes issues des tubercules malades. Aucun virus susceptible de provoquer des nécroses tuberculaires comme le virus du Rattle du tabac, le virus du Mop Top de la pomme de terre ou le virus de la nécrose du tabac n'a été mis en évidence.

L'isolement sur tabac du virus $Y$ et sa réinoculation à des pommes de terre saines permet de reproduire les nécroses sur tubercules, ce qui n'est pas le cas avec le virus $X$; la présence de celui-ci au sein de l'inoculum ne modifie pas l'expression de ces symptômes.

L'isolat du virus $Y$ en cause appartient au sous-groupe $Y^{N}$ par ses propriétés sérologiques et son comportement sur Nicotiana tabacum; cependant, les réactions qu'il induit sur les feuilles de pomme de terre (mosaïque forte de type $Y^{O}$ ) et sur d'autres plantes hôtes le distinguent de souches $Y^{N}$ classiques ou d'autres isolats de PVY également associés à des nécroses tuberculaires. Cette maladie semble en effet proche d'affections décrites sur d'autres variétés au cours des dernières années en Europe de l'Est.
\end{abstract}

potyvirus / étiologie

Summary - Superficial ringspot necrosis of potato tubers: a recent disease caused by Potato virus $Y$. $A$ disease observed for the first time in 1988 and still present in 1989-1990 occurred in Lebanon on seed potatoes of the Lola cultivar. Tuber surface showed severely necrotic areas which varied in shape. Generally these had the appearance of fairly regular bows and rings (figs 1, 4), firstly protruding, then later becoming sunken and dark brown (fig 3). In some cases the skins were cracked. Under these superficial necroses, the adjacent flesh was brown, but there was no deep abnormality inside the tuber (figs 2, 6). The first symptoms appeared rather suddenly at the harvest period in a large number of tubers; in the others, they occurred during the first weeks of storage. The disease was tuber- and sap-transmitted. In tubers or leaves from infected plants, 2 viruses, potato virus $Y(P V Y)$ and potato virus $X$ (PVX) were identified by ELISA and IEM, the former virus being systematically present. These serological detection methods, biological indexing, bait plants, and dip-method did not reveal any other viruses such as those which normally induce tuber necrosis, like tobacco rattle virus, potato mop-top and tobacco necrosis virus. PVY and PVX isolated from potato plants were mutiplied on tobacco and back-inoculated onto potatoes; the same necrotic symptoms on tubers were obtained with either PVY alone or associated with PVX. PVX alone did not provoke necrosis symptoms, nor did it modify the reaction of the plants when present in the inoculum with PVY. So it was clearly demonstrated that PVY was alone responsible for the necrotic reactions in the tubers. This PVY isolate was characterized as PVYN, first serologically by using Mabs specific to this PVY subgroup, and also from the reactions that it induced on Nicotiana tabacum $L$ Xanthi, Samsum or White Burley. However, when its host range and its effect on potato foliage were taken into consideration, it appeared distinct from our standard PVYN strain (tobacco veinal necrosis strain). Our results were also different from those of other authors who previously isolated PVYN from tubers showing identical necrosis. Indeed, such tuber necrotic ringspot diseases, consistently associated with PVY, have previously been reported in several European countries, including Hungary and Yugoslavia. 


\section{INTRODUCTION}

Une affection particulière sur plants de pomme de terre de la variété Lola, a été mise en évidence au Liban pour la première fois en 1988. Elle se caractérise par la présence sur tubercules d'importantes nécroses superficielles de forme variable qui apparaissent à la récolte et s'intensifient en cours de conservation. Les campagnes 1989 et 1990 ont confirmé la persistance de cette nouvelle maladie.

Un programme d'études multidisciplinaires mycologie, bactériologie, nématologie, virologie - a été mis en œuvre en 1989 au centre INRA de Rennes, afin de tenter de préciser l'étiologie de cette maladie. Les études microbiologiques ont montré l'absence de bactéries (Sailly, comm pers) ou de champignons parasites, à l'exception d'un isolat de Fusarium solani au faible pouvoir pathogène et considéré comme incapable de provoquer les altérations des tubercules (Tivoli, comm pers). Les analyses de sols des parcelles attaquées ont mis en évidence la présence d'une population importante de Nématodes appartenant à une espèce très fréquente en culture Globodora rostochiensis, mais n'ont révélé aucun des genres vecteurs de virus, en particulier Trichodorus, vecteur du principal virus nécrogène sur tubercules, le virus du Rattle du tabac (TRV) (Mugniery, comm pers). Les premiers essais de piégeage de ce virus, ou de l' 1 des 3 autres également transmis par le sol, le virus du Mop-Top de la pomme de terre (PMTV), le virus des anneaux noirs de la tomate (TBRV) et le virus de la nécrose du tabac (TNV), se sont révélés infructueux.

Cependant, en l'absence d'autres causes, physiologiques ou parasitaires, la démonstration de la transmission de la maladie de tubercules mères à leur descendance a fait privilégier l'hypothèse de la nature virale de l'affection. Celle-ci a été renforcée par les résultats concluants des essais de transmission mécanique de la maladie à des plantes saines. Le présent article décrit la mise en évidence du virus $Y$ (PVY) et montre qu'il est bien la cause des symptômes observés.

\section{MATÉRIEL ET MÉTHODES}

\section{Matériel}

\section{Matériel d'étude}

Huit tubercules de pomme de terre de la variété Lola, présentant des symptômes de la maladie, ainsi que des échantillons du sol prélevés dans les mêmes parcelles au Liban au moment de la récolte nous ont été adressés par le service commercial de la société "Comptoir agricole du Levant".

\section{Virus}

Des souches de référence des virus $Y O, Y N, Y C, X$ (PVX) et A (PVA) faisant partie de la collection du laboratoire, ont été utilisées. Les virus $S$ (PVS) et $M$ (PVM) nous ont été fournis par la station de Landerneau de la Fédération nationale des producteurs de plants de pomme de terre.

\section{Plantes-tests}

Un lot de pommes de terre de la même variété, certifié sain, aimablement fourni par la société "Bretagne plants" a été utilisé lors des études de transmission à la descendance.

L'indexage et la caractérisation biologique de l'isolat ont été réalisés à partir de la gamme d'espèces et variétés de plantes tests suivantes : Capsicum annuum $\mathrm{L}$ Yolo Wonder, Chenopodium amaranticolor Coste et Reyn, $C$ murale $\mathrm{L}, C$ quinoa Willd, Cucumis sativus $\mathrm{L}$ Marketer, Datura metel L, Gomphrena globosa L, Datura stramonium L, Lycopersicon esculentum Mill, Nicotiana tabacum L Samsum, $N$ tabacum $\mathrm{L}$ Xanthi nn, $N$ tabacum L White Burley, Phaseolus vulgaris L, Physalis floridana Rydb, Pisum sativum L, Petunia hybrida Vilm, Solanum demissum A6 (Solanum tuberosum $L x$ $\mathrm{S}$ demissum).

\section{Réactifs sérologiques}

Des immun-sérums polyclonaux produits au laboratoire spécifiques des virus $Y, X, A$ et Enroulement (PLRV) de la pomme de terre, ainsi que des immunsérums polyclonaux commerciaux (Bioreba - Suisse) antivirus $S$ et antivirus $M$ de la pomme de terre ont été utilisés. Des réactifs monoclonaux spécifiques de sous-groupes du virus $Y: Y N$ (Bioreba) et $Y O-Y C$ (produits au laboratoire), ont également été mis en œuvre pour la caractérisation immunologique.

\section{Méthodes}

\section{Indexage biologique}

Pour chaque source virale, 4 plantes par espèce et variété - avec 2 répétitions - ont été inoculées par frottis à partir de 2 inoculums distincts:

- d'une part, $1 \mathrm{~g}$ de fragment de tubercule, prélevé au niveau de zones nécrosées du périderme et du parenchyme cortical, a été broyé à $12^{\circ} \mathrm{C}$ dans $5 \mathrm{ml}$ de tampon Sörensen 0,02 mol. I $^{-1} \mathrm{pH} 7,2$, contenant $2 \%$ de diéthyldithiocarbamate de sodium, 
- d'autre part, $1 \mathrm{~g}$ de feuille prélevé sur plante issue d'un tubercule nécrosé, a été broyé dans $3 \mathrm{ml}$ de tampon Sörensen.

Les inoculations ont été réalisées en parallèle sur des plantules au stade 4-5 feuilles. L'incubation a été menée en conditions contrôlées, sous serre hermétique aux pucerons, à $18-20^{\circ} \mathrm{C}$ et avec un photopériodisme naturel de jour croissant.

Nos résultats ont été interprétés à partir des compilations établies par De Bokx (1987) (tableau l) et Beczner et al (1984) relatives aux réactions induites par les principaux virus de la pomme de terre sur une gamme d'hôtes différentiels. Le travail de De Bokx (1975) concernant le Potato Aucuba Mosaic Virus (PAMV) a également été pris en compte.

\section{Transmission de pomme de terre à pomme de terre}

Comme précédemment, l'inoculum a été prélevé soit directement sur les tubercules nécrosés, soit sur les plantes feuillées qui en sont issues; il a été inoculé à des plantules de Lola saines au stade 5-6 feuilles, à raison de 5 plantes-tests et 2 répétitions pour chaque source virale. Dans certains cas, il n'y a pas eu de transmission directe de pomme de terre à pomme de terre, mais un passage sur un hôte intermédiaire, $N$ tabacum Xanthi. Toutes les plantes ont été élevées dans un mélange de terre et tourbe stérile, sous serre hermétique aux pucerons, à $18-20^{\circ} \mathrm{C}$.

La durée totale des expériences est de $150 \mathrm{j}$ après l'inoculation, qui se décomposent en une première phase de $90 \mathrm{j}$ de culture et une seconde phase après récolte de $60 \mathrm{j}$ de conservation, à $12^{\circ} \mathrm{C}$ et à l'obscurité. Une notation visuelle des symptômes est réalisée à intervalles réguliers.

\section{Technique ELISA}

La technique double sandwich standard (Clark et Adams, 1977) a été mise en œuvre, avec des IgG dosées à $1 \mu \mathrm{g} / \mathrm{ml}$, sauf pour le PVA $(5 \mu \mathrm{g} / \mathrm{ml})$, et un conjugué lgG-phosphatase alcaline dilué au 1/1 000 , sauf pour le PVA (1/500). La réaction est effectuée sur plaques de microtitration Falcon «pro - bind". La lecture des densités optiques est réalisée à l'aide d'un spectrophotomètre “Titerteck - Multiskan" (Flow Lab) après $2 \mathrm{~h}$ d'incubation enzyme-substrat à la température ambiante du laboratoire.

\section{Microscopie électronique}

Les observations en microscopie électronique ont été réalisées à l'université de Rennes I, sur un appareil Philips CM 12. Les techniques de «dip-method» (Brandes, 1957) et de «derrick - decoration» (Milne et Luisoni, 1977) ont été mises en œuvre à partir d'extraits prélevés sur tubercules et sur feuilles. Les préparations sur grilles collodionnées et carbonées ont été contrastées à l'aide d'acétate d'uranyle à $2 \%$ en solution aqueuse.

\section{Plantes pièges}

Trois espèces ont été utilisées : $C$ sativus susceptible de piéger le TRV et TBRV, $N$ tabacum Xanthi capable de retenir le TRV et le TNV, $N$ debneyi Domin, plante piège du PMTV. De jeunes plantules ont été placées dans chaque échantillon de sol provenant des parcelles atteintes; elles ont été maintenues pendant 2 mois à $18-20^{\circ} \mathrm{C}$ sous serre hermétique aux pucerons. À la fin de cette période, les racines de ces plantes ont été prélevées et broyées dans le tampon

Tableau l. Réactions induites par les principaux $\left(^{*}\right)$ virus de la pomme de terre sur une gamme d'hôtes différentiels (D'après De Bokx, 1987).

AMV APLV APMV PAMV PMTV PVA PVM PVS PVT PVX PVY TNV TRV

Capsicum annuum $\mathrm{L}$ Chenopodium amaranticolor

Coste et Reyn

Chenopodium quinoa Wild

Datura metel L

Datura stramonium L

Gomphrena globosa L

Lycopersicon esculentum Mill

Nicotiana tabacum $\mathrm{L}$

Phaseolus vulgaris $\mathrm{L}$

Physalis floridana Rybd

Solanum demissum $A_{6}$
L

L

(L)

$\begin{array}{ll} & \text { L } \\ & \text { L } \\ \text { S } & \text { (L) } \\ & \\ & \text { (L) } \\ & \text { S } \\ \text { S } & \\ \text { L } & \text { L } \\ \text { L } & \end{array}$

$S$
$S$
$L$

$\begin{array}{cccc} & & L & S \\ & S & L & (L)\end{array}$

LS S L (L)

L/S S

$\mathrm{S}$

(L) $\mathrm{S} S$ . 
Sörensen ( $1 \mathrm{~g} / 5 \mathrm{mg}$ ); les extraits ainsi obtenus ont été inoculés sur 3 plantes indicatrices, $C$ amaranticolor, $N$ tabacum Xanthi et $P$ vulgaris, mises à incuber en chambre climatisée dans 2 conditions de température, $15 \pm 1{ }^{\circ} \mathrm{C}$ (conditions favorables à l'extériorisation du PMTV) et $20 \pm 1^{\circ} \mathrm{C}$.

\section{RÉSULTATS}

\section{Symptomatologie sur la variété de pomme de terre Lola}

Les symptômes typiques de la maladie sont observés sur tubercules. En conditions naturelles de culture, ils se manifestent dès la maturité et s'intensifient en cours de conservation. Des renflements apparaissent à la surface des tubercules (figs 1 et 2); ils prennent souvent la forme, soit de cercles plus ou moins réguliers (fig 3 ), soit de fils arqués ou encore d'arabesques (fig 4). De couleur claire, peu distinguables de la couleur naturelle du périderme et peu saillants au départ, ces renflements deviennent progressivement très visibles, boursouflés et de couleur brun foncé. Au cours de la conservation, il apparaît une dessiccation des parties atteintes, accompagnée d'un affaissement tissulaire (fig 5). Selon l'intensité de la réaction, ces dépressions peuvent former des crevasses profondes de 2 à $4 \mathrm{~mm}$ dans le cortex. Dans tous les cas, ces symptômes restent localisés au parenchyme cortical, qui est coloré en brun à l'endroit des nécroses péridermiques (figs 2 et 6 ). Aucune atteinte nécrotique n'est observée dans la partie interne, correspondant au cylindre central des tubercules.

Lorsque des tubercules porteurs de nécroses sont plantés en serre, ils donnent naissance à des plantes feuillées présentant une mosaïque parfois assez prononcée (fig 7), mais générałement faible.

\section{Mise en évidence de l'origine virale de la maladie}

Deux séries d'expériences basées sur des inoculations mécaniques ont mis en évidence l'origine virale de la maladie.

\section{Transmission directe à la descendance}

Les transmissions ont été réalisées à partir des 8 tubercules porteurs de symptômes caractéristi- ques de nécroses. Après une saison de culture en serre dans des conditions visant à empêcher toute contamination extérieure, les mêmes altérations ont été observées sur la descendance : selon les plantes mères, $50-55 \%$ des tubercules fils au moment de la récolte, $70-80 \%$ après 3 semaines de conservation présentaient des nécroses superficielles.

Dans le cas d'une infection primaire - une plantule de pomme de terre saine est inoculée à partir d'un extrait de tubercule nécrosé - les symptômes apparaissent $15 \mathrm{j}$ après la date d'inoculation, sur les feuilles ayant reçu l'inoculum, d'abord sous forme de lésions locales, puis de nécroses nervaires à la face inférieure du limbe (fig 8); ces nécroses gagnent ensuite le pétiole, puis la tige où elles forment des stries nécrotiques; parallèlement, il y a un jaunissement quasi généralisé des espaces internervaires. Ces symptômes apparaissent ensuite sur plusieurs étages des feuilles néoformées. Au stade final, il y a chute des feuilles et, dans les cas extrêmes, dépérissement total de la plante. Ce type de réaction traduit le plus communément une infection primaire par le virus $Y$, précisément par les souches ordinaires $\left(Y^{O}\right)$ ou les souches $Y C$ de ce virus. Une grande partie des tubercules fils obtenus à partir de ces plantes présentent des nécroses superficielles, les pourcentages de tubercules atteints et les conditions d'expression de ces symptômes étant très voisins de ceux constatés après infection secondaire.

\section{Transmission à la descendance après passage sur un hôte intermédiaire}

Lorsque l'expérience précédente est réalisée avec passage sur un hôte intermédiaire, $N$ tabacum Xanthi, les mêmes réactions sont obtenues sur pomme de terre (feuilles et tubercules). Sur tabac, des symptômes apparaissent également sur les feuilles néoformées - taches blanchâtres et nécroses nervaires, déformation du limbe et chute prématurée des feuilles - ainsi que sur les tiges - nécroses en stries, puis brunissement nécrotique généralisé jusqu'au collet; ces symptômes sont proches de ceux habituellement causés par les souches nécrotiques du virus $Y$, mais d'intensité nettement plus forte.

\section{Identification des virus présents}

Quatre techniques ont été mises en œuvre pour détecter et identifier le ou les virus présents au 
niveau des nécroses tuberculaires : la technique Elisa, la microscopie électronique, l'indexage biologique, les plantes pièges. L'ensemble des résultats est récapitulé dans le tableau II.

\section{Technique ELISA}

Le test Elisa a été mis en œuvre, soit directement sur des extraits des 8 tubercules, soit sur les plantes feuillées issues de ces tubercules, pour vérifier la présence des 6 principaux virus de la pomme de terre, les virus $Y, X, A, S, M$ et le virus de l'enroulement (PLRV). Les 8 tubercules sont porteurs de virus $Y$; les tubercules 3 et 5 sont de plus coïnfectés par le virus $X$. Dans les 2 cas, ces virus se retrouvent dans les plantes feuillées correspondantes. En revanche, tous les tests se sont révélés négatifs pour les 4 autres virus de la pomme de terre, PVA, PVS, PVM et PLRV.

\section{Microscopie électronique}

L'observation en microscopie électronique - dip method - d'extraits prélevés à la périphérie des nécroses tuberculaires a permis de détecter dans tous les échantillons la présence de particules filamenteuses flexueuses, de longueur très variable et de 12-14 nm de largeur. Aucune particule de nature virale parasphérique, bacilliforme ou en bâtonnet, n'a été mise en évidence.

L'application de la technique d'IEM «Derrick Decoration» a mis en évidence dans les échan- tillons provenant des tubercules 3 et 5,2 types de particules; une partie d'entre elles seulement est entourée d'anticorps en présence, soit de sérum anti-PVY, soit de sérum anti-PVX; dans les échantillons prélevés à partir des 6 autres tubercules, toutes les particules sont "décorées" par le sérum anti-PVY et aucune par le sérum anti-PVX.

Les mêmes observations ont été réalisées à partir des plantes feuillées issues des tubercules nécrosés.

\section{Indexage biologique}

L'indexage biologique a été mis en œuvre sur une large gamme de plantes-hôtes pour révéler d'éventuels virus autres que ceux détectés par voie sérologique. Les mêmes résultats ont été obtenus à partir des tubercules et des plantes feuillées correspondantes (tableau III).

Les réactions sur l'ensemble des plantes tests permettent de distinguer 2 groupes de tubercules: les tubercules 3 et 5 d'une part, les tubercules 1, 2, 4, 6, 7 et 8 d'autre part.

Dans les tubercules 3 et 5 , la présence du virus $X$ est confirmée par les lésions locales induites sur $C$ annuum et $G$ globosa et par l'infection systémique sur $D$ stramonium, plante immune au virus $Y$. Le type de lésions locales sur feuilles détachées de $S$ demissum "A6" est révélateur de la présence conjointe dans ces échantillons du virus $Y$, ce que paraît traduire également l'extériorisation de lésions locales sur

Tableau II. Récapitulation des résultats de détection des virus à partir des 8 tubercules d'origine de la variété Lola.

\begin{tabular}{|c|c|c|c|c|c|c|c|c|c|c|c|c|}
\hline \multirow{2}{*}{$\begin{array}{l}\text { Tubercules } \\
\text { d'origine }\end{array}$} & \multicolumn{2}{|c|}{ Dip-method } & \multicolumn{3}{|c|}{ IEM et Elisa } & \multicolumn{3}{|c|}{ Indexage biologique } & \multicolumn{4}{|c|}{ Plante pièges } \\
\hline & $\begin{array}{r}\text { Particu } \\
\text { flexueuses }\end{array}$ & les & PVY & $P V X$ & autres & $P V Y$ & $P V X$ & autres & TRV & TBRV & $T N V$ & PMTV \\
\hline 1 & + & - & + & - & - & + & - & - & - & - & - & - \\
\hline 2 & + & - & + & - & - & + & - & - & - & - & - & - \\
\hline 3 & + & - & + & + & - & + & + & - & - & - & - & - \\
\hline 4 & + & - & + & - & - & + & - & - & - & - & - & - \\
\hline 5 & + & - & + & + & - & + & + & - & - & - & - & - \\
\hline 6 & + & - & + & - & - & + & - & - & - & - & - & - \\
\hline 7 & + & - & + & - & - & + & - & - & - & - & - & - \\
\hline 8 & + & - & + & - & - & + & - & - & - & - & - & - \\
\hline
\end{tabular}

* Seuls les virus A, S, M et PLRV de la pomme de terre ont été recherchés par la technique Elisa en dehors des virus $Y$ et $X$. 
Figs 1 et 2. Tubercules de la variété Lola à la récolte.

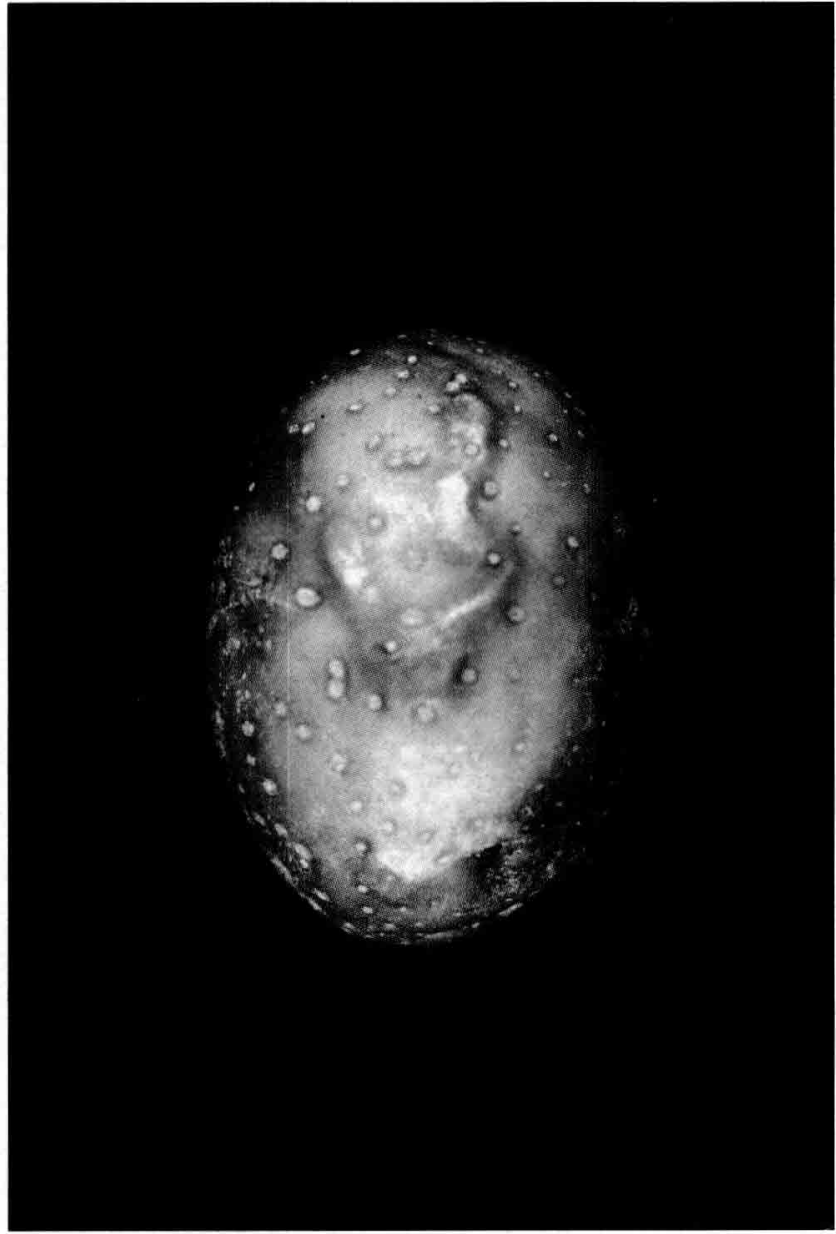

Fig 1. Premiers symptômes : renflements irréguliers superficiels.

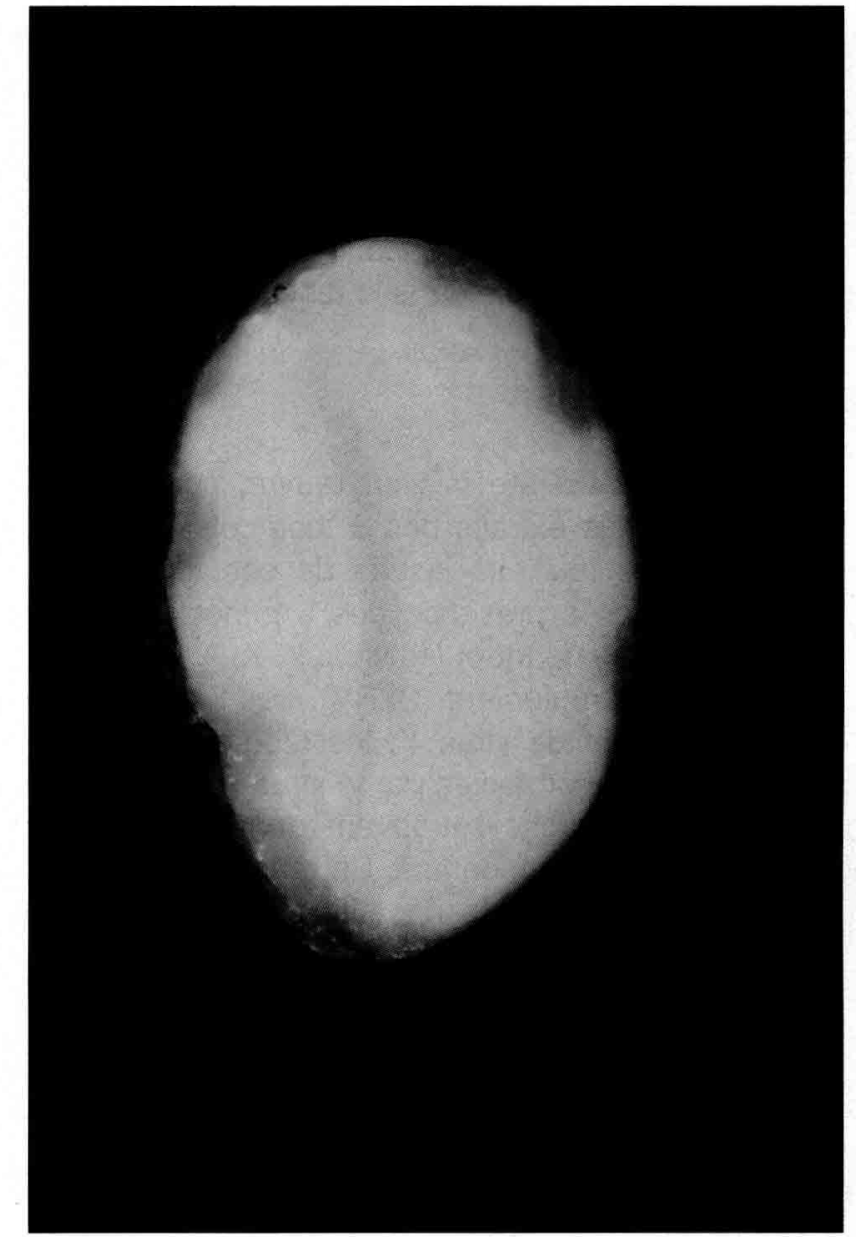

Fig 2. Coupe transversale du tubercule montrant les colorations brunes sous-jacentes aux nécroses externes.

Figs 3 et 4 . Tubercules de la variété Lola en conservation, 3 semaines après la récolte.

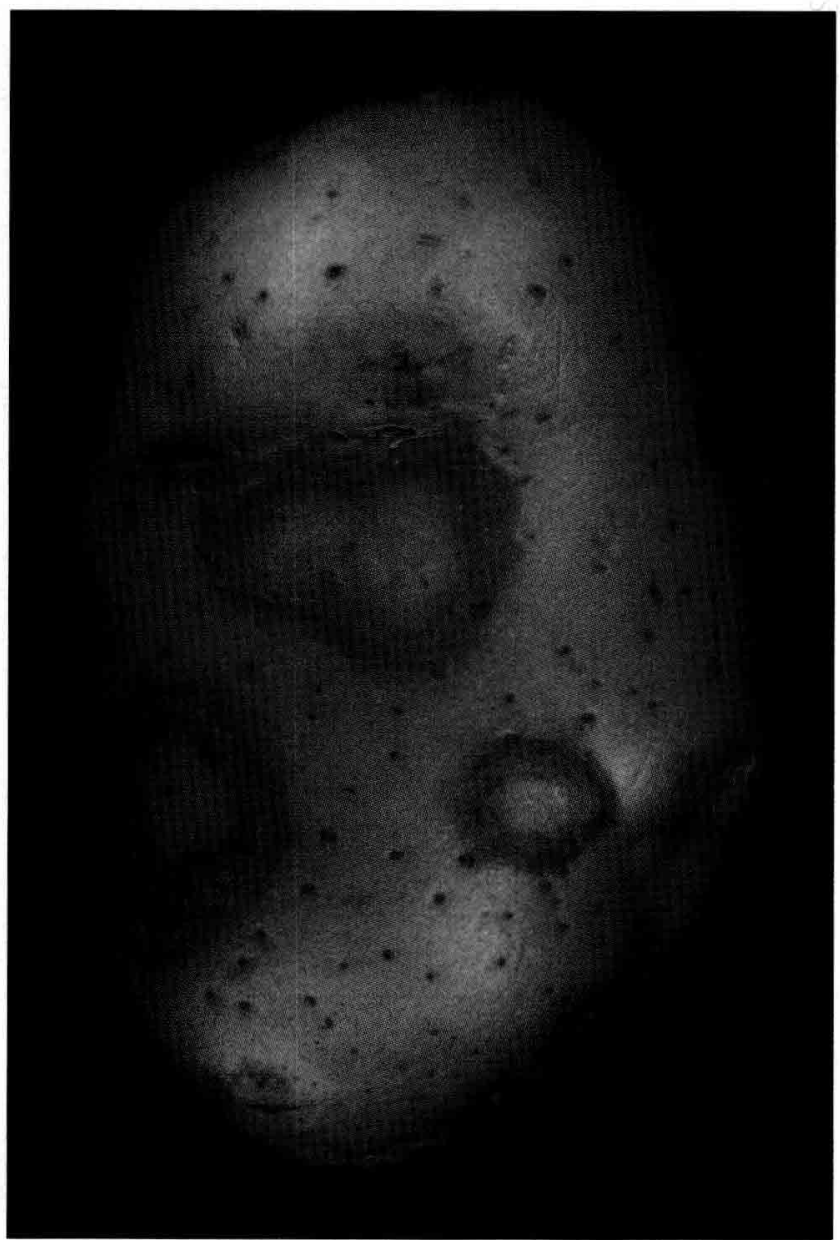

Fig 3. Anneaux superficiels.

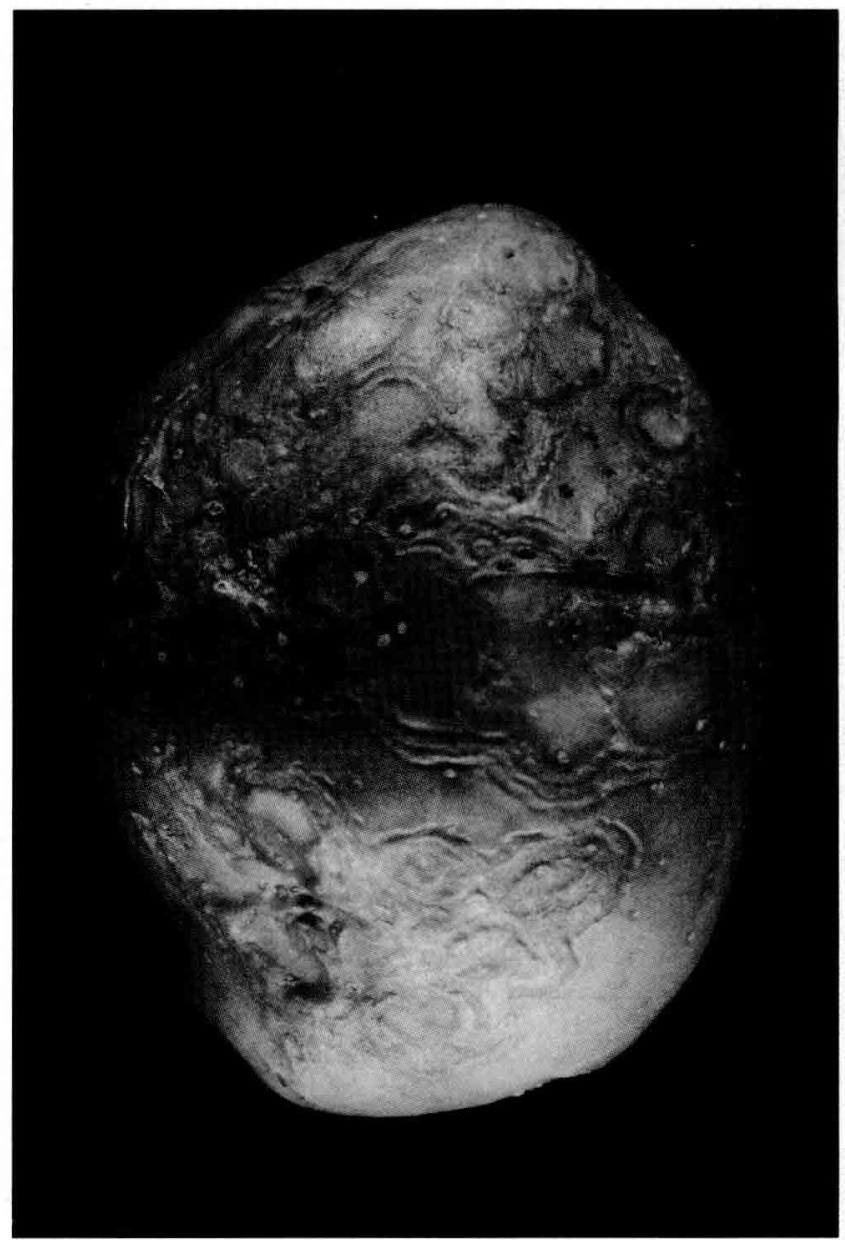

Fig 4. Bourrelets superficiels de forme variée. 
Figs 5 et 6. Tubercules de la variété Lola en conservation, 8 semaines annòs la rócolte.

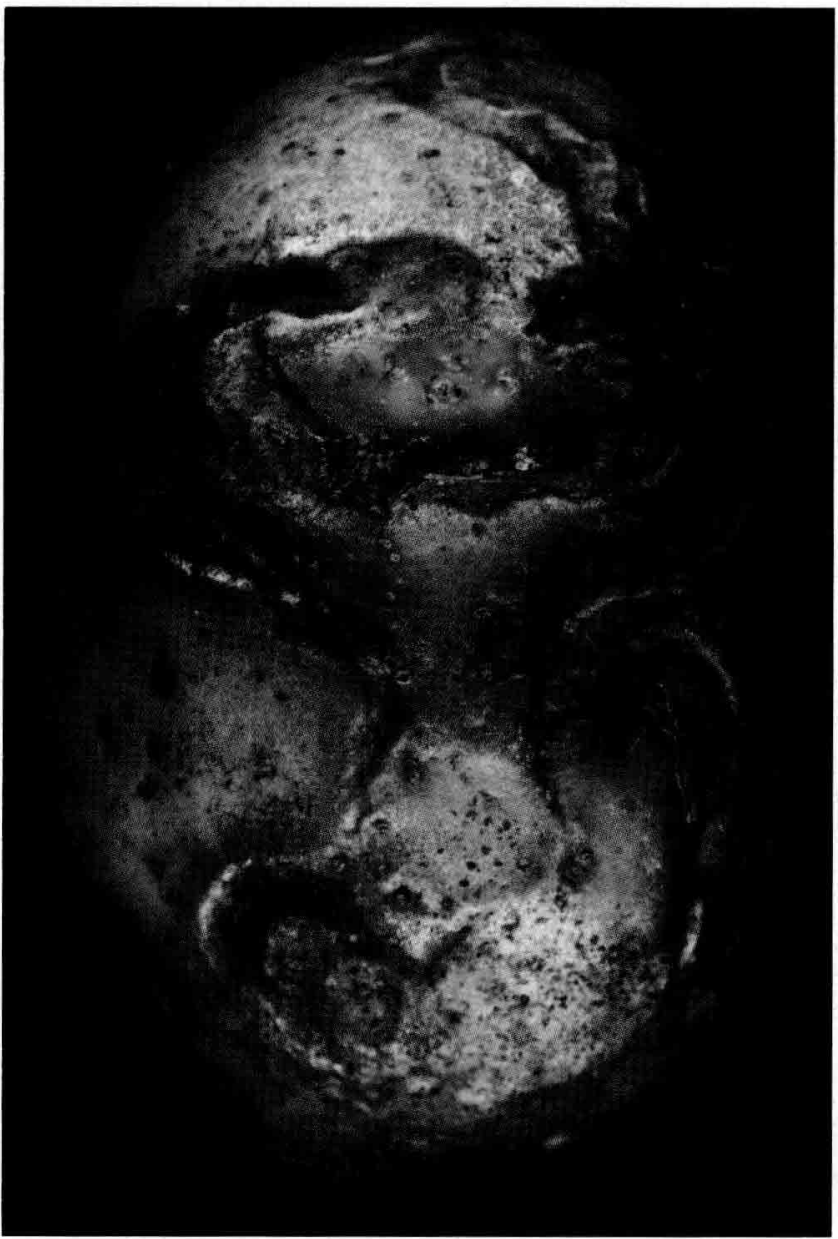

Fig 5. En surface : dépressions évoluant en crevasses.

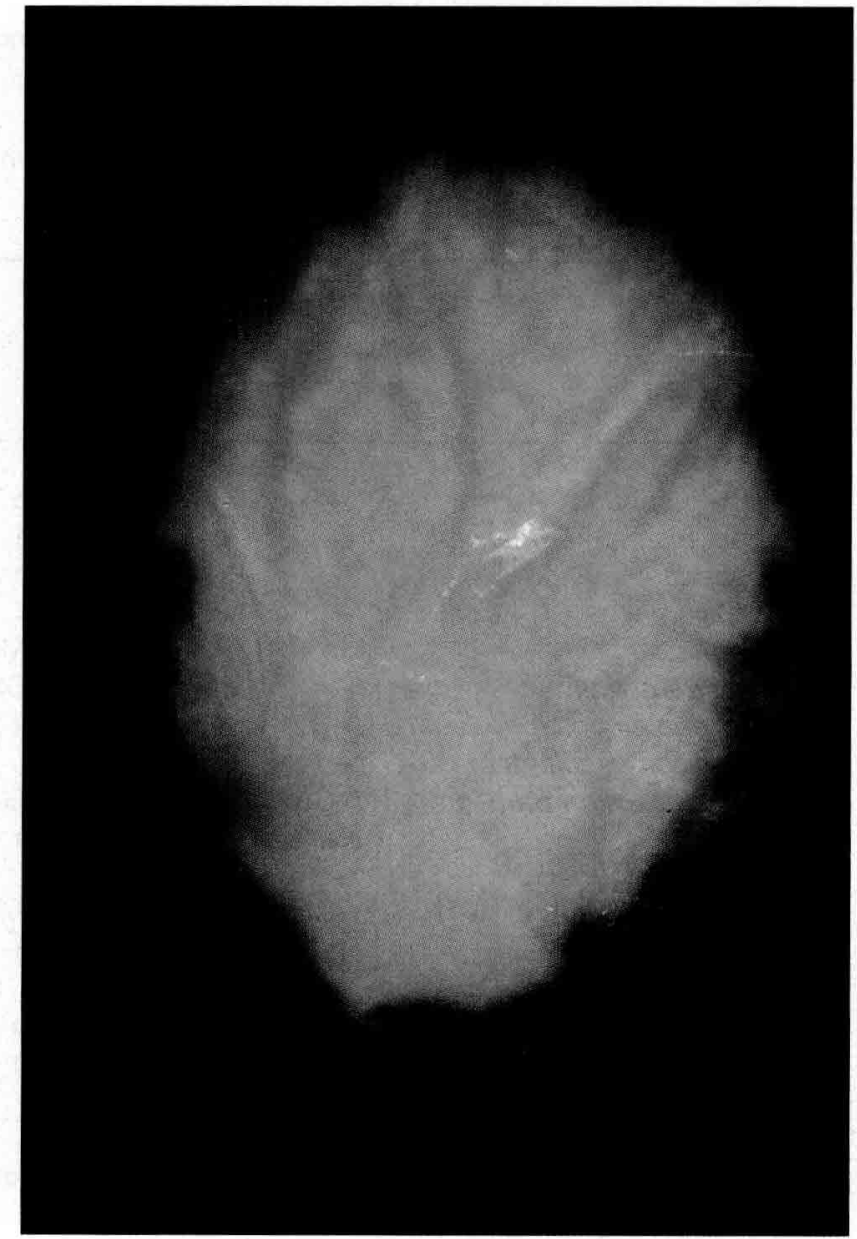

Fig 6. En coupe : lésions brun-foncé restant localisées au parenchyme cortical.

Figs 7 et 8 . Symptômes sur la partie aérienne de plants de la variété Lola.

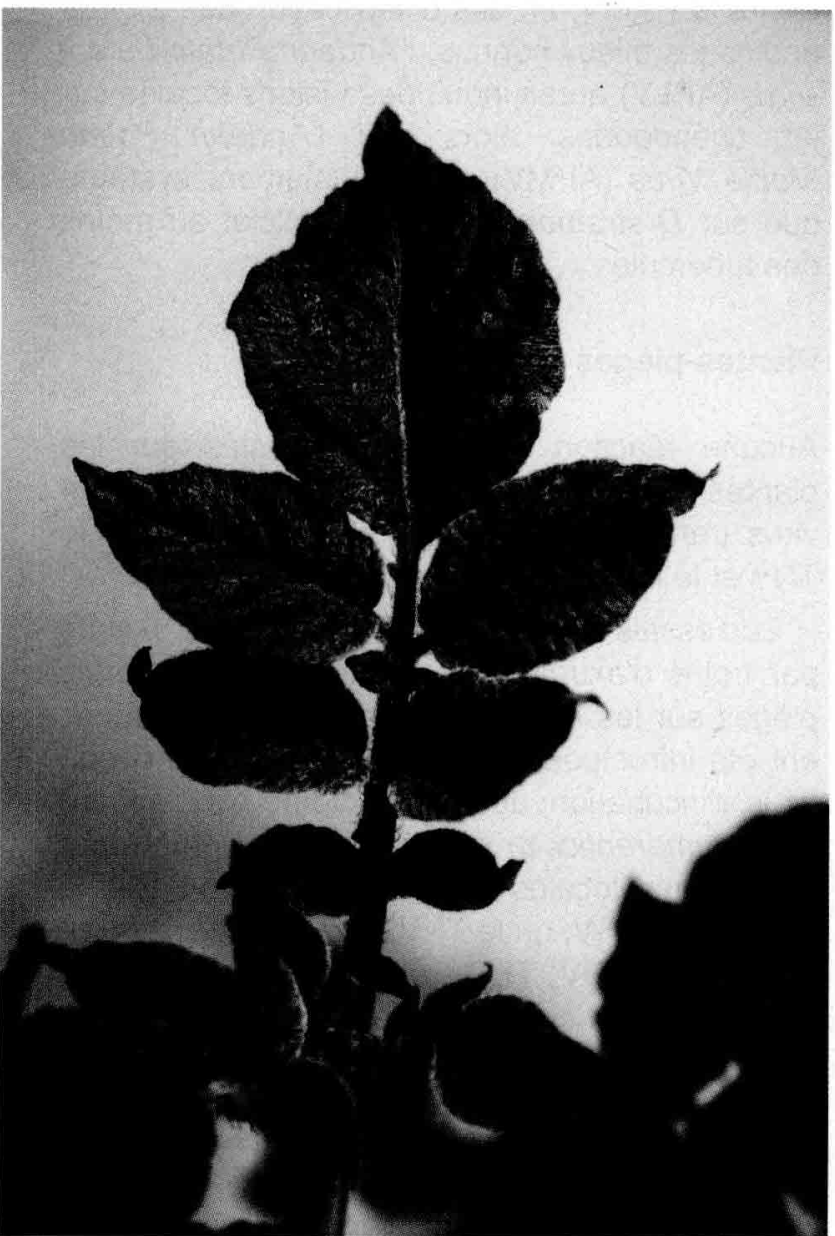

Fig 7. Mosaïque et frisolée assez intenses après infection secondaire.

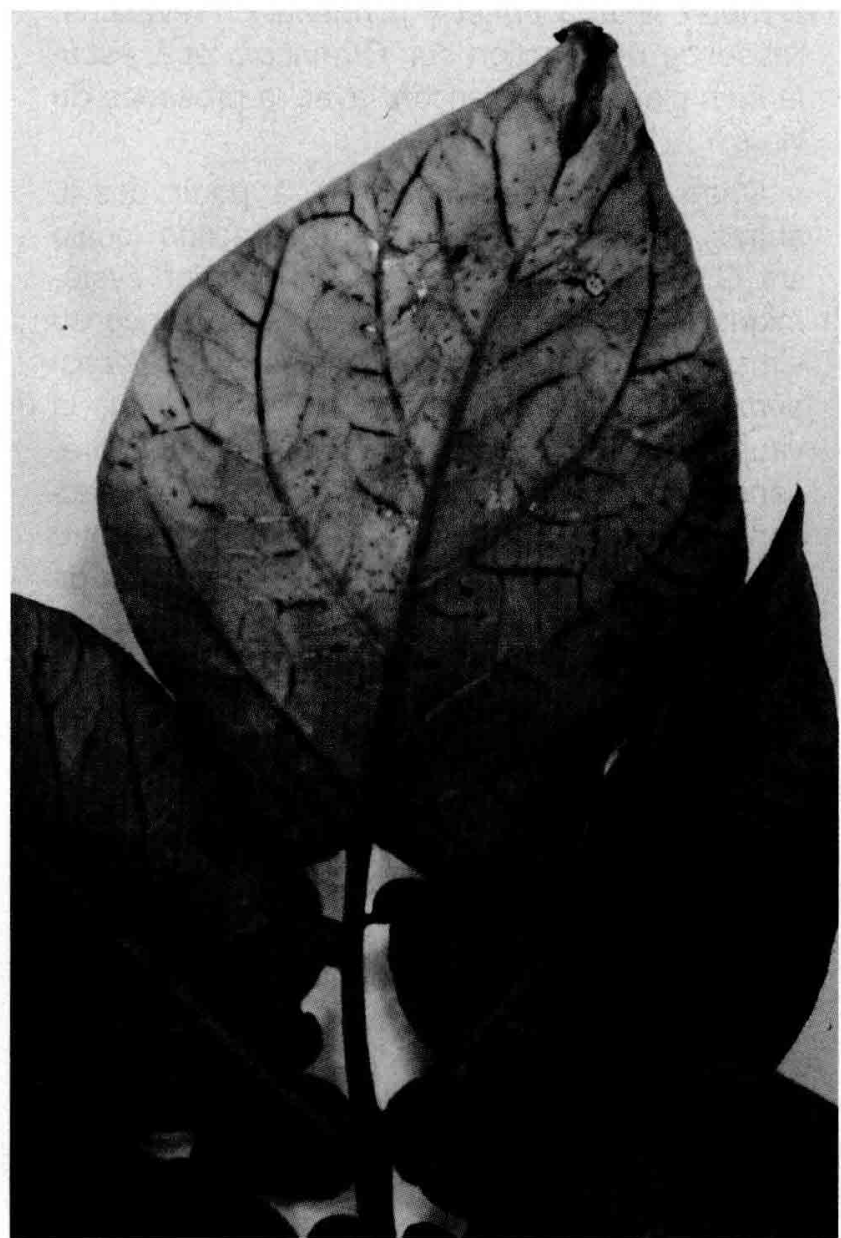

Fig 8̂. Ṅecroses nervaires à ia face infierieure du ïmbe après contamination primaire. 
Tableau III. Résultats de l'indexage biologique à partir des 8 tubercules d'origine de la variété Lola et des plantes feuillées correspondantes.

Tubercule ou plant-feuillée

\begin{tabular}{|c|c|c|c|c|c|c|c|c|}
\hline Plantes-tests & 1 & 2 & 3 & 4 & 5 & 6 & 7 & 8 \\
\hline Capsicum annuum & - & - & Lln & - & $\operatorname{LIn}$ & - & - & - \\
\hline Chenopodium amaranticolor & - & - & $\operatorname{Lln}$ & - & LIn & - & - & - \\
\hline Chenopodium quinoa & - & - & Llc & - & Llc & - & - & - \\
\hline Cucumis sativus & - & - & - & - & - & - & - & - \\
\hline Datura metel & Mo & Mo & LIn, Mo & Mo & LIn, Mo & Mo & Mo & Mo \\
\hline Datura stramonium & - & - & Mo, Chl & - & Mo, Chl & - & - & - \\
\hline Gomphrena globosa & - & - & LIn & - & Lin & - & - & - \\
\hline Lycopersicon esculentum & - & - & - & - & - & - & - & - \\
\hline Nicotiana tabacum Samsum & $\begin{array}{c}\mathrm{Ne}-\mathrm{Ga} \\
\mathrm{Na}\end{array}$ & $\begin{array}{c}\mathrm{Ne}-\mathrm{Ga} \\
\mathrm{Na}\end{array}$ & $\begin{array}{c}\mathrm{Ne}-\mathrm{Ga} \\
\mathrm{Na}\end{array}$ & $\begin{array}{c}\mathrm{Ne}-\mathrm{Ga} \\
\mathrm{Na}\end{array}$ & $\begin{array}{c}\mathrm{Ne}-\mathrm{Ga} \\
\mathrm{Na}\end{array}$ & $\begin{array}{c}\mathrm{Ne}-\mathrm{Ga} \\
\mathrm{Na}\end{array}$ & $\begin{array}{c}\mathrm{Ne}-\mathrm{Ga} \\
\mathrm{Na}\end{array}$ & $\begin{array}{c}\mathrm{Ne}-\mathrm{Ga} \\
\mathrm{Na}\end{array}$ \\
\hline Phaseolus vulgaris & - & - & - & - & - & - & - & - \\
\hline Physalis floridana & $\begin{array}{c}\text { Mo, Chl } \\
\mathrm{Na}\end{array}$ & $\begin{array}{c}\text { Mo, Chl } \\
\mathrm{Na}\end{array}$ & $\begin{array}{l}\text { LIn, Mo } \\
\quad \mathrm{Na}\end{array}$ & $\begin{array}{c}\text { Mo, Chl } \\
\mathrm{Na}\end{array}$ & $\begin{array}{l}\text { Lln, Mo } \\
\mathrm{Na}\end{array}$ & $\begin{array}{c}\text { Mo, Chl } \\
\mathrm{Na}\end{array}$ & $\begin{array}{c}\mathrm{Mo}, \mathrm{Chl} \\
\mathrm{Na}\end{array}$ & $\begin{array}{c}\text { Mo, Chl } \\
\mathrm{Na}\end{array}$ \\
\hline Pisum sativum & - & - & - & - & - & - & - & - \\
\hline Petunia hybrida & Mo & Mo & Mo & Mo & Mo & Mo & Mo & Mo \\
\hline Solanum demissum $\mathrm{A}_{6}$ & $\operatorname{Lin}$ & Lln & $\operatorname{LIn}$ & LIn & $\operatorname{Lin}$ & $\operatorname{Lln}$ & $\operatorname{LIn}$ & LIn \\
\hline
\end{tabular}

- : pas de symptômes; Mo : mosaïque; Llc : lésions locales chlorotiques; Lln : lésions locales nécrotiques; Chl: : chloroses nervaires et internervaires; $\mathrm{Ne}$ : nécroses nervaires et internervaires; $\mathrm{Na}$ : nanisme; Ga : gaufrage.

$C$ amaranticolor et $C$ quinoa, et de mosaïque sur $D$ metel, $N$ tabacum et $P$ floridana. En revanche, l'absence de réaction sur $C$ annuum et $L$ esculentum n'est pas en accord avec la présence du virus $\mathrm{Y}$.

Chez les plantes inoculées à partir des 6 autres tubercules, l'absence de réaction locale sur $G$ globosa et $C$ annuum et d'infection systémique sur $D$ stramonium exclut la présence du virus $X$. Le type de lésions locales sur $S$ demissum “A6» élimine, comme précédemment, le virus $A$ au profit du virus $Y$; cependant, si la présence de ce dernier est confirmée par les réactions sur tabac, $P$ floridana et $D$ metel entre autres, elle est infirmée par la non-apparition de lésions locales sur $C$ amaranticolor et $C$ quinoa et de symptômes systémiques sur $L$ esculentum et $C$ annuum - ces derniers étant sensibles au moins à certaines souches de PVY.

Dans tous les cas, il n'y a pas d'évidence de la présence d'autres virus; aucun symptôme ne s'est manifesté sur $P$ vulgaris, ce qui confirme l'absence du virus $M$ et tend à exclure aussi I'AMV et le TNV; la non apparition de réactions sur $C$ sativus, autre indication de l'absence du virus $M$, traduit aussi celle du TRV et du TBRV; le défaut d'infection systémique sur $P$ sativum exclut le PAMV; en cas d'implication des 2 virus andins les mieux connus, l'Andean Potato Latent Virus (APLV) aurait induit des lésions locales sur les chénopodes, alors que l'Andean Potato Mottle Virus (APMV) est normalement systémique sur $D$ stramonium, ce qui l'exclut au moins des tubercules $1,2,4,6,7$ et 8 .

\section{Plantes-pièges}

Aucune réaction ne s'est manifestée sur les plantes des 3 espèces utilisées pour piéger les 4 virus transmis par le sol : le TRV, le TBRV, le TNV et le PMTV.

Les essais de transmission d'un éventuel virus par frottis d'extraits des racines de ces plantes pièges sur les feuilles de 3 espèces indicatrices ont été infructueux quelles que soient les conditions d'incubation; aucun symptôme n'est apparu sur $C$ amaranticolor qui réagit normalement par des lésions locales à l'infection par le TRV, le PMTV, le TBRV, ou le TNV, ou sur $P$ vulgaris, indicateur de TRV, TBRV et TNV, ou sur $N$ tabacum Xanthi nn susceptible de révéler le TRV, le PMTV et le TBRV. 
En conclusion, seuls 2 virus ont été mis en évidence; le virus $X$ est présent dans les tubercules 3 et 5 et absent chez les 6 autres, quelle que soit la technique mise en œuvre; la présence du virus $Y$ dans les 8 tubercules est attestée par les résultats obtenus en sérologie, même si elle est controversée par ceux de l'analyse biologique.

\section{Démonstration de l'induction des nécroses superficielles par le PVY isolé d'un des tubercules naturellement infectés}

Le virus $Y$ a été isolé à partir du tubercule 2 , le virus $X$ à partir du tubercule 3 . Tous 2 ont été transmis à $N$ tabacum cv Samsum, directement depuis la pomme de terre dans le cas du virus $Y$, après passage sur $D$ stramonium, plante immune au virus $Y$, dans le cas du virus $X$.

Quatre lots de pommes de terre saines de la variété Lola ont été inoculés mécaniquement sur feuilles, respectivement par l'isolat $Y$ seul, l'isolat $X$ seul, les 2 isolats en mélange (PVY + PVX «artificiel») et par un inoculum prélevé sur la descendance du tubercule 3 contenant naturellement les 2 virus $Y$ et $X$ (PVY + PVX «naturel»).

Des symptômes primaires de lésions chlorotiques sur les feuilles inoculées et de mosaïques caractéristiques de l'un et l'autre virus sur les feuilles néoformées commencent à se manifester 15 après l'inoculation. Dans tous les cas, excepté chez les plantes infectées par le virus $X$ seul, des nécroses apparaissent sur les tubercules fils; elles sont identiques à celles observées sur les tubercules d'origine; leurs conditions d'expression sont également les mêmes : au moment de la récolte, 30 à $40 \%$ environ des tubercules en sont atteints contre $75 \%$ en moyenne quelques semaines plus tard (tableau IV). II n'y a pas de différences significatives entre les plantes infectées par le virus $Y$ seul et celles infectées par les mélanges naturel ou artificiel de virus $X$ et de virus $\mathrm{Y}$.

Le virus $Y$ est donc seul responsable de l'induction de ces nécroses, la présence du virus $X$ $n$ 'influençant pas leur expression. L'inoculation de retour sur tabac à partir de ces nouveaux tubercules fils nécrosés confirme la présence de l'un et l'autre virus.

\section{Première caractérisation de l'isolat de PVY nécrogène}

Les premiers résultats d'indexage sont contradictoires : les symptômes sont de type Yo sur pomme de terre en infection primaire, mais plutôt de type $Y^{N}$ sur tabac; par ailleurs, des réactions inhabituelles pour le virus $Y$ sont apparues sur différentes plantes tests. L'isolat de PVY inducteur des nécroses tuberculaires, nommé PVYNN a donc été comparé à des souches de référence $Y O, Y N, Y C$ sur une gamme d'hôtes différentiels et caractérisé sérologiquement.

\section{Caractérisation sérologique}

La technique «Derrick - Décoration» d'IEM mise en œuvre à partir d'Ac Mc spécifiques de sousgroupes du virus $Y\left(Y^{N}\right.$ d'une part, $Y O-Y C$ d'autre part) révèle que l'isolat étudié ici appartient au sous-groupe $Y N$; il n'y a décoration des particules qu'en présence d'anticorps spécifiques des souches $Y \mathrm{~N}$. Ce résultat a été confirmé par la technique Elisa.

Tableau IV. Extériorisation de nécroses sur tubercules de la variété Lola après inoculation mécanique sur feuillage par les virus $Y$ et $X$, seuls ou en mélange.

\begin{tabular}{|c|c|c|c|c|c|c|}
\hline \multirow[t]{2}{*}{ Inoculum } & \multirow[t]{2}{*}{$\begin{array}{c}\text { Nombre de } \\
\text { tubercules récoltés }\end{array}$} & \multicolumn{5}{|c|}{$\begin{array}{l}\text { Pourcentages de tubercules nécrosés } \\
\text { après récolte et en cours de conservation }\end{array}$} \\
\hline & & $0 j^{*}$ & $10 j$ & $20 j$ & $30 j$ & $60 j$ \\
\hline Y seul & 73 & 40 & 52 & 68 & 70 & 70 \\
\hline$X$ seul & 46 & 0 & 0 & 0 & 0 & 0 \\
\hline$Y+X$ «artificiel» & 35 & 30 & 40 & 78 & 78 & 78 \\
\hline$Y+X$ «naturel» & 45 & 36 & 48 & 72 & 76 & 76 \\
\hline
\end{tabular}

\footnotetext{
" Nombre de jours après récolte
} 


\section{Caractérisation biologique}

Les résultats de la comparaison de l'isolat $Y N N$ avec les souches de référence $Y O, Y^{N}$ et $Y C$ figurent dans le tableau $V$. L'isolat $Y N N$ se comporte comme la souche $Y^{N}$ sur la majorité des plantes testées, excepté sur $C$ amaranticolor où il n'induit aucune réaction, locale ou systémique. Les symptômes sur les 3 cultivars de tabac, Xanthi, Samsum et White Burley sont à peu près identiques quelle que soit la souche; ils sont dans le cas de YNN légèrement plus forts qu'après inoculation par $Y N$. Sur $P$ floridana et $D$ metel, autres espèces différenciatrices des souches $P V Y$, les réactions sont identiques pour $Y N N$ et $Y N$. $C$ murale et $D$ stramonium sont immunes vis-à-vis des 4 inoculums expérimentés.

\section{DISCUSSION}

En l'absence d'autres causes physiologiques ou parasitaires, les nécroses sur tubercules de pomme de terre sont généralement attribuées au virus du Rattle du tabac (TRV) - la maladie est connue en France sous le nom de «liège de la pomme de terre" (Kerlan, 1989) - ou plus rarement au virus du Mop-Top de la pomme de terre (PMTV); celui-ci n'a encore jamais été détecté en France, mais il semble s'être développé au cours des dernières années en Europe du Nord (Ryden et al, 1989). Plusieurs autres virus de la pomme de terre sont également capables de provoquer des nécroses superficielles et/ou in- ternes sur les tubercules de certaines variétés: le virus de la nécrose du tabac (TNV), qui est transmis, comme le PMTV, par un champignon du sol (Peters, 1981), le virus de la mosaïque "aucuba" de la pomme de terre (PAMV) qui induit en conservation des nécroses très proches de celles que nous avons observées (Kassanis et Govier, 1972), le virus de l'enroulement de la pomme de terre (PLVR) qui provoque un réseau nécrotique apparaissant en coupe sous la forme de points (Peters et Jones, 1981); la souche "paracrinkle" du virus $M$ a été aussi rendue responsable de nécroses sur tubercules (Loughnane, 1958).

Au cours de la dernière décennie, des symptômes assez voisins de ceux apparus sur la variété Lola ont été décrits sous le nom de "Tuber Necrotic Ringspot Disease» (TRND) en Hongrie (Beczner et al, 1984), en Allemagne (Weidemann, 1985), en Yougoslavie (Buturovic et Kus, 1989; Kus, 1990), et en Autriche (Schiessendoppler, 1990). Plusieurs virus ( $M, S, X, Y)$ ont été mis en évidence par ces auteurs dans les plantes atteintes, mais jamais le TRV, le PMTV ou le TNV; le virus $Y$ est constamment associé à la maladie, mais le postulat de $\mathrm{KOCH}$ (reproduction des symptômes après isolement et réinoculation de la souche virale) n'a jamais été totalement démontré. Précédemment, en France dans la région d'Orléans, des nécroses tuberculaires sur des pommes de terre de consommation avaient également été associées au virus $\mathrm{Y}$ (Guillou et Kerlan, comm pers).

Tableau V. Comparaison de l'isolat $Y^{N N}$ et de souches de référence $Y^{N}$, $Y^{O}$ et $Y^{C}$ sur différentes plantes hôtes.

\section{Plantes tests}

\begin{tabular}{lc} 
& $Y N N$ \\
\hline C amaranticolor & - \\
C murale & - \\
$D$ metel & $\mathrm{Mof}, \mathrm{Ga}$ \\
$D$ stramonium & - \\
$N$ tabacum Samsum & $\mathrm{Ne}, \mathrm{Ga}, \mathrm{Na}$ \\
$N$ tabacum White Burley & $\mathrm{Ne}, \mathrm{Ga}, \mathrm{Na}$ \\
$P$ floridana & $\mathrm{Llc}, \mathrm{Chl}, \mathrm{Ga}$ \\
S demissum $\mathrm{A}_{6}{ }^{*}$ & $\mathrm{LIn}$
\end{tabular}

\section{Souche ou isolat}

$Y^{N} \quad$ YO $\quad Y C$

$\begin{array}{cc}\text { Llc } & \text { Llc } \\ - & - \\ \mathrm{Mo} & \mathrm{Mo} \\ - & - \\ \mathrm{Chl} \rightarrow \mathrm{Ma} & \mathrm{Chl} \rightarrow \mathrm{Ma} \\ \mathrm{Chl} \rightarrow \mathrm{Ma} & \mathrm{Chl} \rightarrow \mathrm{Ma} \\ \mathrm{LIn}, \mathrm{Ne}, \mathrm{Na}, \mathrm{Fl} & \mathrm{Lin}, \mathrm{Ne}, \mathrm{Na}, \mathrm{FI} \\ \operatorname{Lin} & \mathrm{LIn}\end{array}$

\footnotetext{
* Test sur feuille détachée (en lumière continue à $22^{\circ} \mathrm{C}$ avec hygrométrie constante). Mo : mosaïque; Mof : forte mosaïque; Ga : gaufrage; $\mathrm{Ne}$ : nécroses systémiques nervaires et/ou internervaires; $\mathrm{Na}$ : nanisme; Chl : chloroses nervaires et internervaires; $\mathrm{Fl}: \mathrm{flé}-$ trissement; LIc : lésions locales chlorotiques; LIn : lésions locales nécrotiques; Ma : marbrure; - : pas de symptôme, pas d'infection systémique (contrôle par test Elisa).
} 
Les travaux réalisés ici montrent que les réactions de nécroses annulaires superficielles sont bien dues au virus $Y$ qui est le seul qui soit systématiquement présent. Excepté le virus $X$, aucun des autres virus de la pomme de terre, notamment ceux capables de provoquer des nécroses sur tubercules, n'a été détecté. L'absence de réactions sur les plantes pièges tend à exclure les virus transmis par le sol (TRV, TBRV, TNV, PMTV); la transmissibilité par voie mécanique élimine l'hypothèse du PLRV; la non-infection de $C$ annuum, plante indicatrice du PAMV permet de supposer l'absence de ce virus; il en est de même pour le virus $M$ qui induit normalement des lésions locales sur 2 des plantes testées, $G$ globosa et $P$ vulgaris.

L'isolat de PVY en cause peut être rangé d'après ses caractéristiques sérologiques dans le sous-groupe $Y^{N}$. Cependant, par ses propriétés biologiques, il semble s'agir d'un isolat particulier différant des souches $Y^{N}$ de référence, notamment par son inaptitude à infecter $C$ amaranticolor. Les isolats nécrogènes hongrois et yougoslaves dénommés $P V Y^{R}$ appartiennent également au sous-groupe $Y N$, mais à la différence de l'isolat nécrogène français, l'isolat hongrois induit des lésions locales sur $C$ quinoa et $C$ murale et infecte systémiquement $L$ esculentum et $C$ annuum - cette dernière espèce est hôte du PVY (De Bokx, 1987), mais n'est pas sensible à toutes les souches (Gebre Selassie et al, 1985) -; de plus l'isolat yougoslave provoque sur tabac des réactions plus faibles qu'une souche $Y^{N}$ typique (Buturovic et Kus, 1989), alors que c'est le contraire pour l'isolat français.

Les souches de PVY naturellement nécrogènes sur tubercules appartiennent généralement au sous-groupe $Y C$ (Beemster et De Bokx, 1987); elles provoquent chez certaines variétés possédant le gène dominant $\mathrm{Nc}$, une réaction d'hypersensibilité qui se traduit sur les feuilles et les tiges de pomme de terre par des symptômes des stries nécrotiques en pointillés ("stipplestreak necrosis") proches de ceux que nous avons observé après infection primaire sur la variété Lola; ces souches $\mathrm{YC}^{\mathrm{C}}$ sont peu répandues en France (Kerlan et al, 1985). Les souches de type YO peuvent également provoquer des nécroses tuberculaires chez un petit nombre de variétés, alors que dans le cas des souches $\gamma^{N}$ cette hypersensibilité, si elle existe, serait très exceptionnelle (Breemster et De Bokx, 1987). Pour sa part, Jones (1987, 1990), met en évidence ce type de réactions sur 12 variétés inoculées avec des isolats $Y O$ et $Y C$ ou encore avec les virus $A$ et $V$ de la pomme de terre, alors que les isolats $Y N$ induisent une infection systémique.
La similitude des symptômes, leur apparition assez soudaine au moment de la récolte ou peu de temps après, le fait qu'il s'agisse d'un isolat de type $Y N$, constituent autant de points de convergence entre nos observations et celles réalisées en Europe de l'Est. II serait intéressant d'étudier si les variétés atteintes dans ces pays (Igor, Désirée, Saskia, Rosalie, Mona Lisa) possèdent en commun avec Lola un gène de sensibilité particulière à certaines souches du virus $Y$. II apparaît également important de comparer les propriétés biologiques et sérologiques des différents isolats nécrogènes. Sur le plan agronomique, plusieurs questions se posent, quant à l'origine des contaminations, du mode de conservation de l'inoculum, des facteurs de dissémination en conditions naturelles et de la sensibilité des autres variétés, en premier lieu de celles qui sont cultivées en France et plus largement en Europe de l'Ouest.

\section{REMERCIEMENTS}

Nous avons le plaisir de remercier l'Institut du tabac de Bergerac, ainsi que Messieurs les conservateurs des Jardins botaniques de l'université Louis Pasteur à Strasbourg et de la ville de Rennes, qui nous ont fourni les graines des différentes espèces végétales utilisées dans cette étude.

\section{RÉFÉRENCES}

Beczner L, Horvath J, Romhanyi I, Forster H (1984) Studies on the etiology of tuber necrotic ringspot disease in potato. Potato Res 27, 339-352

Beemster ABR, De Bokx JA (1987) Viruses, viroids, mycoplasmas and diseases with a virus-like aetiology: survey of properties and symptoms. In: Viruses of potatoes and seed-potato production (JA De Bokx, JPH Van Der Want, eds) Pudoc, Wageningen, 84-113

Brandes J (1957) Eine elektronenmikroskopische Schnellmethode zum Nachweiss Faden und Sträbchenformiger Viren insbesondere in Kartoffeldumkerdeimen. Nachrichtenbl Dtsch Pflanzen Schutdienst Braunschw 9, 151-152

Buturovic D, Kus M (1989) The occurence of potato tuber ring necrotic diseases in Yougoslavia. EAPR Virology Section Meeting, Bologne, juin 1989 (Abstr)

Clark MF, Adams AM (1977) Characteristics of the microplate method of enzyme-linked immunosorbent assay for the detection of plant viruses. J Gen Virol $34,475-483$

De Bokx JA (1975) Reactions of various plant species to inoculation with potato aucuba mosaic virus. Potato Res 18, 397-409 
De Bokx JA (1987) Characterization and identification of potato viruses and viroids: biological properties. In: Viruses of potatoes and seed-potato production (JA De Bokx, JPM Van Der Want, eds) Pudoc, Wageningen, 58-79

Gebre Selassie K, Marchoux G, Delecolle B, Pochard $E$ (1985) Variabilité naturelle des souches de virus $Y$ de la pomme de terre dans les cultures de piment du Sud-Est de la France. Caractérisation et classification en pathotypes. Agronomie 5, 621-630

Jones RAC (1987) Problems associated with potyviruses in potato certification-field inspection and serological testing. Eur Mediterr Plant Prot Organ (EPPO Bull) 17, 125-130

Jones RAC (1990) Strain group specific and virus hypersensitive reactions to infection with potyviruses in potato cultivars. Ann App/ Biol 117, 93-105

Kassanis B, Govier DA (1972) Potato aucuba mosaic virus. CMI/AAB Desc Plant Viruses 98

Kerlan C (1989) La maladie du liège ou "Rattle" de la pomme de terre. In : La protection de la pomme de terre, ITPT Paris, 71-76

Kerlan C, Valade C, Guillou M (1985) Production de plants de pomme de terre en France : différentes formes de virus Y. Pomme Terre Fr 431, 323-326
Kus M (1990) Potato tuber ring necrosis disease (PTRND) in Slovenia. /te Conf Trienn EAPR Edimbourg, 8-13 juin 1990, Abstr 196

Loughnane JB (1958) A necrosis of potato caused by the paracrinkle virus. Proc 3rd Conf Potato Virus Dis, Lisse Wageningen 1957, 179-183

Milne RG, Luisoni E (1977) Rapid immune electron microscopy of virus preparations. In: Methods in virology (GK Maramorosch et H Koprowski, eds) Acad Press New York London, 256-289

Peters D (1981) Tobacco necrosis virus. In: Compendium of potato diseases (WJ Hooker, ed) Am Phytopath Soc, Saint-Paul Minnesota, 86-87

Peters D, Jones RAC (1981) Potato leafroll virus. In: Compendium of potato diseases (WJ Hooker, ed). Am phytopath Soc, Saint-Paul Minnesota, 86-87

Ryden K, Lövgren L, Sandgren M (1989) Investigation on potato mop-top furoviruses in Sweden. Eur Mediterr Plant Prot Organ Publ (EPPO Bull) 19, 579593

Schiessendoppler E (1990) PVY as causal agent of tuber necrotic ring disease. Ile Conf Trienn EAPR Edimbourg, 8-13 juin 1990, Abstr 194-195

Weidemann HL (1985) Ringsymptome an Kartoffelknollen: Kartoffelvirus $Y$ als vermutliche Ursache. Kartoffelbau 36, 356-357 